\begin{tabular}{|c|}
\hline $\begin{array}{l}\text { A partir dos conceitos de } \\
\text { onipotência e de } \\
\text { ambivalência matemas } \\
\text { em mães de crianças } \\
\text { dbentes, a autora } \\
\text { pergunta-se sdbre aquilo } \\
\text { de que se queixam as } \\
\text { mães, ilustrandb as } \\
\text { questões de perda, de } \\
\text { castração, de desilusãoe } \\
\text { de constituição do dojeto } \\
\text { por meio de um caso } \\
\text { clínico depsicose. } \\
\text { Ambivalência materna; } \\
\text { psicose; onipotência } \\
\text { materna }\end{array}$ \\
\hline
\end{tabular}

A partir das conceitos de cnipotência e de ambivalência matemas em mães de crianças dbentes, a autora pergunta-se sobre aquilo de que se queixam as mães, ilustrandb as questões de perda, de castração, de desilunãoe de constituição do dbjeto por meio de um caso clínicodepsicose. Ambivalência materna; psicose; cnipotência materna

MATERNAL COMPLAINT Fronconcepts as all powerfulness and matemal ambivalence at diseased dilldren'smothers, the author asks abatt mother's complaint, illustratingher hypethesis abat loss, castration, illusionand

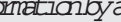
cirical starycresychis. psychosis; matemal ponerfiliness

\section{A QUEIXA MATERNA}

\author{
Michèle Benhaim
}

Tradução: Inesita Machado

\section{INTRODUÇÃ O}<smiles>[10BH]</smiles>

que se queixam as mães?

Num primeiro momento, se nos basearmos naquilo que é enunciado, elas queixam-se de que seu filhovai mal.

Em seguida, durrante a evolução desse último, e de modo mais inconsciente, num segundo momento, elas queixam-se de que justamente seu fitho vai bem.

Entre um momento e outro, entre aquele em que a criança vai mal e aquele em que ela está melhor, a queixa aparece de várias formas, com conteúdos bastante recorrentes, principalmente o db(s) sacrifício(s) da educação da criança, certamente difícil, e, num registro mais atual, os sacrifícios gerados pelos cuidados (acompanhamento, pagamento dos transportes, ausência nas tarefas doméstices...).

Enfim, em situaçães mais intrincadas no plano psicopatológico, elas queixam-se da loucura e do medo que lhes inspiram seus filhos, reconhecidos como loucos quando seus comportamentos não deixam mais muito espaço para a negação ou para a denegação.

Psicanalista, mâ̂tre de conférences na Universidade da Provence, em Aix-Marselha I nas disciplinas Psicopatologia da Criança e do Adolescente, autora do livro L'ambivalence de la mère, publicada pela Érès em Paris, em 2001. 
Para introduzir nossa proposta, partamos de duas hipóteses psicopatológicas:

1. A mãe do sujeito psicótico põe seu filho num lugar de objeto de gozo, de capricho, em seu fantasma, e não enuncia nenhuma queixa diretamente a ele, além daquela, bastante estereotipada, que desaparece rapidamente e que ressalta: "Ele não faz nada durante o dia, ele me impede de fazer isso ou aquilo, de viver... Faça alguma coisa" . À medida que notamos uma evolução favorável da criança, a queixa mais subjetiva aparece e, tendo se tomado próxima de uma posição psíquica ocupada por uma mãe comum, esta põe-se a queixar-se verdadeiramente. Não importa que forma adquira aqui a questão, o que nos interessa é que a criança parece mudar de lugar e de estatuto à medida que se torna objeto da queixa. Esta constatação leva-nos à questão inicial: de que se queixa, portanto, a mãe?

2. Do fato de que seu fi lho não tenha feito com que ela escapasse a seu destino, a castração. O fi lho não a preencheu, então, nesse tempo da desilusão que está se realizando, a mãe se queixa. A primeira pessoa castrada na dialética intra-subjetiva é a mãe. É aí que se encontra, antes de mais nada, a posição da castração. E é porque ele captura esta castração ligada à dialética do desejo que o jovem sujeito poderá, por sua vez, ter essa falta.

Esses dois pontos relativos à questão da queixa irão se artiarlar com a questão da ambivalência da mãe, de que falaremos mais tarde, com a seguinte enunciação prévia: "A queixa matema supõe o reconhecimento do dbjeto, no caso, a criança, a experimentação de sua distância (e até mesmo de sua perda) e a recusa desse afastamento" . Assim, a queixa repousa sobre o confronto do sujeito com diferença, com distância, com alteridade do objeto. Podemos dizer, ainda, com separação, isto é, o confronto com essa prova do corte simbólico com o abjeto.

com o dbjetivo de captar a dimensão psíquica essencial, façamos um desvio pelo conceito de dbjeto na psicanálise. Freud diz que "encontrar o objeto é, de um modo propriamente dito, reencontrá-lo". Fintre encontrar e reencontrar estaria a experiência radical e fundadora da perda.

Se tentarmos captar o objeto cronologicamente, constatamos que o primeiro tempo é aquele que faz da perda e da constituição do dbjeto dois fenômenos indissociáveis: é o tempo em que o bebê, incapaz de cuidar de si mesmo, fica entregue aos cuidados de um outro, de quem ele pode esperar que, no melhor dos casos, esses cuidados sejam marcados pelo amor. No laço estreito que une aiidadb e amor, na articulação do vital e do sexulal, elabora-se a separação que repousa sobre a perda do dbjeto, e a vida subjetiva pode então ter início. 
Se é o leite que alimenta, é o seio que a criança vai perder. Este "dbjeto" da autoconservação será impossivvel de reencontrar como tal. Elle está perdido por princípio, sempre procurado, nunca reencontrado. No limite, "perda do objeto" ou "objeto perdido" são pleonasmos: a separação, a perda estão compreendidas no dojeto, já que o dbjeto não poderia ser constituído antes de perder-se. Seria esse irremediável que alimenta a queixa em cada um e especificamente na mãe, tendo como pano de fundo uma irredutivel melancolia...

O segundo tempo vê o dbjeto perder-se cessando de ser parcial e tomando-se objeto total, "na época", diz Freud nos Três ensaios (1905), "em que se toma possível para a criança formar a representação global da pessoa à qual pertencia o órgão que lhe proporcionava a satisfação" (p. 72) .

Finalmente, o terceiro tempo repousa sobre o dbjeto perdido do amor edípico impossível.

O corte simbólico com o abjeto será determinado pelo lugar ocupado pela criança no fantasma matemo, criança metonímia do desejo de falo na mãe, ou criança metáfora de seu amor pelo pai. O exemplo clássico do Pequeno Hans, sobre o qual Lacan se estendeu no Seminário IV, A relação de cbjeto, proferido em 1957-8, de ter sido inteiramente pasto, sem que se tratasse somente de seu wiwi-macher, num lugar de objeto metonímico do falo que sua mãe não tem e jamais terá, tem o preço, para a criança, da neurose fóbica. Não mais podendo sustentar o lugar em que é posto pela mãe, ele se "entrincheira".

Antes de ser, entretanto, um objeto imaginário para sua mãe, a criança é, durante um tempo, um objeto real. Num lugar de falo para ela, esta o "suga" realmente (como diz Lacan em seu Seminário sobre As formaçães do inconsciente, proferido em 1957-8) . Uma espécie de objeto interno, de necessidade, devendo passar por essa posição para esperar tomar-se objeto extemo, de desejo. "Tomar-se mãe" permitiria talvez essa passagem da criança do estado de objeto de necessidade, para a mãe, para o estado de abjeto de desejo.

Se retamarmos o percurso, de objeto in utero a criança passa a ser objeto intemo, de necessidade, e depois dbjeto extemo, de desejo, para atingir a possibilidade de se separar da mãe: seria assim a passagem da mãe do ódio ao amor, depois do amor ao ódio, e finalmente à ambivalência, isto é, este amor matemo nãotodb? Tomada dbjeto de desejo, a criança pode ser des-sujeitada da necessidade da mãe, a metáfora patema pode se inscrever, e a criança pode se tomar sujeito, confrontadb ao significante da falta matema e ao desejo desta. 
Nessas condições, o segundo tempo do Édipo toma-se possível: ao interdito edipiano enunciado pelo pai à criança "não dormirís com tua mãe", este pode ser significado à mãe como "não reintegrarás teu produto" . Eis aqui de que modo o amor devorador da mãe acaba por encontrar seu limite e ver-se barrado. "Amar é devorar", diz Winnicott (1969)... A criança, "para o seu bem", sai dessa posição ideal a partir da qual tanto ela quanto a mãe poderiam se satisfazer e em que a criança preenchia a função de objeto metonímico.

No entanto, lembramos que, num primeiro tempo, é porque a criança foi o dbjeto real para a mãe que esta pôde investi-la.

\section{A AMBIVALÊNCIA \\ MATERNA}

A hipótese da necessidade da ambivalência materna tem importância de um ponto de vista estrutural, isto é, como algo que necessariamente estrutura o amor matemo, temperado pelo ódio, para autorizar a criança a se separar daquilo que a faz viver, mas que a levaria à morte se disto não se separasse.

Habitualmente pensamos que o amor matemo repousa sobre o mito de um amor não ambivalente, inteiramente devotadb ao dbjeto. Ora, "um grande crocodilo em cuja boca estás, isto é a mãe", diz Lacan em 0 avesso da psicanálise (1991) , fazendo referência aqui, sem dúvida, a uma mãe não ambivalente, nem "su- ficientemente boa", nem "suficientemente cheia de ódio", que sonha com uma criança que não precise de mais nada, confundindo assim necessidade e desejo.

Nessa confusão, a criança permanece camo um objeto real no fantasma materno. Dito de outro modo, em vez de ser revelada uma necessária perda interior, uma relação continua a ser estabelecida, um amor fundado no gozo que visa, finalmente, para a criança, dominar aquilo de que a mãe é objeto submetido. En contrapartida, cativa do gozo da mãe, a criança se vê, por sua vez, submetida a um gozo insubjetivável e se cala, istoé, pára de chamar o autro que lhe dispensava cuidados maternos.

Ora, mãe e filho devem renunciar ao investimento narcísico fundador da inseparável unidade mãefilho. Por trás da mãe há uma muIher que não perdeu completamente seu narcisismo, muito pelo contrário. Para ela é absolutamente necessário que nem tudo esteja investido em seu filho e que ela guarde para si uma parte.

Tanto quanto a criança deve renunciar à mãe (as "castrações" elaboradas por F. Dolto (1984) , e já contidas no "Pequeno Hans", como o formulou Freud, em notas de rodapé, ilustram esse processo) , a mãe deve paralelamente renunciar ao filho como objeto parcial que lhe pertenceria e que ela poderia usar (e abusar) segundo seus "caprichos". Renunciar à criança implica aceitar a castração de seus gozos arcaicas em relação a ela, para não atrasar e menos ainda impedir que se elabore a 
fase edípica, au seja, que ela se apresente ao fillho a partir de então como barrada, faltante. A patologia da criança mostra que, se a castração advém de uma privação ao mesmo tempo real e simbólica em relação a um objeto cujo acesso é proibido, a criança pode representar tal dbjeto para a mãe, e a separação pode se superpor a uma castração, isto é, a uma privação real e simbólica.

Inversamente, a fusão pode se definir como um estado, um lugar em que o sujeito, no amor, imagina o Outro como totalizado, e até mesmo fora do sexo. Se, por definição, o desejo é falta, falha, incerteza, o amor, em tal lugar psíquico, assemelha-se então a um gozo supremo, uma aspiração à eternidade da plenitude.

Esse amor instala-se no lugar de que o desejo foi expulso, com a particularidade dever instalar-se oódio. Fazer um com o outro parece ser 0 destino. Năe ilimitada, istoé, fora da castraçãa, "oceânica" . ódio destruidor naquilo em que se alia ao desejo de assassinato inconsciente, morte que preencheria talvez o sonho desse gozo fusional: a realização da fusão é a morte. É assim que as crianças se vêem investidas da missão totalmente deslocada de curar a mãe no local de suas feridas narcísicas. Situações que, no limite, poderão gerar desejos de morte. 0 sujeito psicótico adverte-nos sobre isso, ele, que mata realmente sua mãe, acreditando assim livrar-se dela de fato.

Sem possibilidade de ser pensado, o ódio em questão permanece como gozo pulsional que não passa pela linguagem. O gozo como satisfação da pulsão escapa aos desfilles do significante: este é interdito ao ser falante. Aqui, a mãe goza com a criança numa unidade ideal. Fora do fantasma, o capricho materno remete ao real, à angústia, ao horror, a um gozo puro, não velado, que captura a criança numa espécie de complementaridade narcísica da mãe, como lugar de projeção absoluta em que se inscreve o ódio inicial, sem avesso, camo reflexo/efeito da pulsão de morte separada aqui daquilo que deveria oaultá-la no silêncio, a pulsão de vida.

O bebê, recusando a separação e o corte do seio matemo, estabelece esta unidade mítica primordial. Submetido ao desmame, por sua prematuridade biológica que o torna absolutamente dependente, e tenob de deixar este dbjeto a, o seio, como uma separação de si mesmo, ele pensa que vai morrer. Apenas a ambivalência que lhe é impasta pela mãe castrada poderá também inscrevê-lo numa ambivalência dialética, em que coexistem, de modo contraditório, a aceitação e a recusa. Inversamente, pode se desenvolver aí esse "verdadeiro apetite pela morte", que é a anorexia mental, essa afecção em que o sujeito, em seu abandono, tenta encontrar um aquém matemo, isto é, aí desaparecer.

A perda do seio, o desmame, é um moobpossivel deentrarna queixa. "Perderoseid", diz B. Jacobi (1998), "significa para a mãe aceitar-se de novona incompletude", lenbrando que "a criança no seio dá à sua mãe um sentimento de completude inigualável, uma experiênciatotalizante..." (p. 57) . 
Enfim, nesse contexto, a criança não é um objeto perdido, pois este teria sustentado o amor, mas um dbjeto real sustentando, a partir desse estatuto, este amor todo-poderoso, incondicional, isto é, ilimitado, que Freud, Klein, Wimnicott já nomearam como ódio original, primordial, inicial.

Na $5^{a}$ Conferência sobre a feminilidade, Freud (1932-3) diz que "a avidez da criança por sua primeira ama de leite é insaciável, e que a criança fica inconsolável com a perda do seio matemo" .

Năe e filho têm de iniciar logo o luto de um e de outro. Para cada um, o dbjeto está para sempre perdido. Inicialmente, a criança não tem o dbjeto, ela é o dbjeto, e, no caso, perdido. Assim, para livrar-se da influência matema na crença em um duplo narcísico, a criança se constitui como outro e escapa do confronto mortífero com o mesmo.

Deste modo, dar a vida supõe um luto não apenas da criança no útero, mas também daquela que acaba de nascer. Ter um fillho é justamente não mais o ter.

Se a criança "fica inconsolável", estaríamos diante de um luto interminável, que sustentaria uma queixa matema que não poderia deixar de enunciar-se, mas que mostraria, justamente, de modb paradoxal, que o dbjeto está mesmo perdido?

Se a mãe aceita renunciar a seu fi tho como dojeto, verdadeiro luto, portanto, numa privação como a do falo, ela só pode fazê-lo por amor a seu filho e por um homem posto aqui no lugar de pai possível. A criança é pasta então como metáfora do amor por esse homem, esse pai. A mãe aceita renunciar àquilo que ela não tem, aceita doar simbolicamente a um pai, a um homem, o filho que ela teve, certamente, como dbjeto real, como dbjeto de gozo, mas que ela já não tem. Se a criança realizar o dbjeto a no fantasma matemo, ela se tomará o dojeto que dotura a falta e é sua encarnação. É por amar e ser amada que uma mãe pode aceitar ser privada de seu filho. Amar é "dar o que não se tem".

Em "Luto e melancolia", Freud (1915) diz que no luto "a realidade pronuncia seu veredicto: o dbjeto não existe mais; e o eu, posto diante da questão de saber se quer parti lhar desse destino, decide, pela soma das satisfaçães narcísicas, permanecer vivo e romper sua ligação com o dbjeto desaparecido" (p. 32). Assim, a mãe renunciará ao fil lho como objeto a e fará, no campo do amor, com que seu narcisismo substitua a "ausência" de relação sexial...

Por que é tão difícil acabar com o espelho da fusão, com a ilusão de um "corpo no corpo", com o fantasma de fazer um com dois? Sem dúvida porque a gravidez supõe que, por um tempo, o princípio de prazer supere o princípio da realidade. Assim, no melhor dos casos, ela pode resultar de um encantamento que, 
contendo seu próprio limite, verá a ruptura inerente ao pôr no mundo resultar de uma dupla perda: a desse estado de encantamento (superposição singular e excepcional do Imaginário e do Real) e a do dbjeto (a criança) . No pior dos casos, ela atingirá o êxtase, e até mesmo a "destnuição" (l'étarrdit), este laço com a mãe de que não podemos nos desembaraçar.

Esse mito da Mãe-Toda diz respeito tanto à mãe quanto ao filho: a criança, em seu movimento de fusão mortífera com a imago matema, a mãe, em sua impossibilidade de se confrontar à castração, tomada ainda mais difícil pela própria gravidez quando tomada estritamente em seu aspecto de completude, ou, mais tarde, do mesmo modo, pelas determinantes do desmame que repousam sobre a ilusão de uma plenitude enfim encontrada.

Clinicamente, vemos manifestar nas mães, talvez como um eco ao bebê que confunde desmame e morte, fantasmas que se baseiam na crença de que desmamar um bebê é matá-lo: pensamos nos medos expressos por mães de recém-nascidos, medo de matá-los, de deixá-los cairr, de jogá-los pela janela...

A hipótese que possibilita introduzir nossa noção de ambivalência é a de que, ao elaborar o ódio contido no amor, e não contrário ao amor (diz-se que uma transferência pode ser negativa, o que não impede que este continue sendo amor) , pode-se contomar o desejo de morte.

Freud dizia que a ambivalência é a oposição de duas tendências existentes e com freqüência um pooler "desigual" . Essa noção de "desigual" é interessante: as pulsões parecem ser convocadas durante as diferentes etapas da matemidade. E, nesse caso, quando algo de uma separação deve se elaborar: parto, desmame, adblescência, etc. Se a mãe não põe aqui sua ambivalência a serviço do corte, se a inscrição da criança na castração de sua mãe não é logo integrada, a pulsão de morte poderá superar a pulsão de vida. É nesse tipo de contexto que ocorrem os infanticídios.

o que põe a relação da mãe com o filho como ambivalente recobre, portanto, aquilo que situamos do lado do ódio necessário para que se elabore a separação. Cada ocorrência de nuptura ao longo da maternidade fará com que a mãe questione mais uma vez a falta e com que ela posicione-se na enunciação de seu desejo.

Quando Winnicott (1969) afirma, a partir de 1948, que "a mãe odeia seu fi lho desde o início", sem dívida faz referência a um distanciamento dessa ordem, contido de igual modo no "suficientemente" de sua mãe boa, e naquilo que se pode chamar de "dilema da função materna", evocando com isso essa extrema necessidade de separar-se de um objeto que depende 
vitalmente de nós: o segundo movimento, em direção contrária ao primeiro, faz com que a questão só se passa resolver nesse compromisso materno que é a ambivalência, pois é difícil não se ver "tooa" quando se é indispensável.

Não mais do que o aspecto inconsolável para a criança da insuficiência do seio matemo, e é o que revelará a queixa, a mãe não se pode satisfazer na medida do amor do dbjeto. É por isso que se separam.

Para Freud (1915) , oódio originário constrói o dojeto sdb a égide da qposição prazer/desprazer. Para este movimento de separação, esse ódio originário adquire uma dimensão simbólica. Graças ao mecanismo de transformação da pulsão em seu contrário (lembremos que este é um dos destinos possíveis da pulsão) , a ambivalência matema repousaria não mais sobre a transformação do amor em ódio, mas sobre a transformação do movimento host il em movimento temo.

Nomeando aquilo que do ódio inscreve-se logo de início no amor, a questão da vida e da morte pode inscrever-se no simbólico em vez de ser mortífera. Esta inscrição é consecutiva ao tempo em que o pai real realiza o distanciamento oferecendo à criança os significantes do pai simbólico, da lei que interdita qualquer retomo, istoé, a inconporação, para a mãe, do conpo de seu filho.

Se o ódio não se manifesta, ou se se manifesta em excesso, aparecem então comportamentos maternos todo-poderosos: Medéia, narcisicamente ferida, deseja ser mais poderosa do que o pai e ilustra isso tragicamente. 
Encontra-se na queixa essa dimensão de ódio, sobretudo se considerarmos que a queixa articula-se com a crítica, ou melhor, com a autocrítica, como nessa queixa infinita em que repousa a melancolia.

$\mathrm{Na}$ origem da queixa materna está a angústia.

A queixa matema parece inscrever-se sobre o impossível de uma separação, sdbre o impassível de um confronto com a perda, isto é, sobre a superposição de um luto irreal izável e de uma perda não integral. Esta queixa baseia-se no dostáculo materno quanto à elaboração de sua posição narcísica, de sua relação particular com a castração, com a questãoda falta.

o ódio na queixa poderia vir desse ódio não simbolizável de um dojeto que odiamos por nos escapar. B. Jacobi (1998) sugere que, "mais do que a perda do abjeto, é a perda do domínio sobre o objeto que poderia alimentar a queixa" (p. 164).

se de fato o ódio tem um objeto, a queixa matema talvez transborde por tê-lo perdido: esta seria o próprio disarrso desta perda.

É o que mostram, de modo recorrente, as relações que as mães de nossos pacientes psicóticos estabelecem com seus filhos. Tomemos o caso de Elise, que, durante as sessões, ao elaborar um pouco as questões de sua história e a posição que ela ocupa no fantasma de sua mãe, toma-se mais autônoma, como se diz nas instituições. De fato, atualmente ela faz com que haja um intervalo 
de duas horas entre sua saída do hospital/dia e a chegada do ônibus que a leva de volta para a casa de sua mãe. Ela fica muito feliz com isso, e ocupa esse tempo com ela mesma, vai a butiques, cafés, vê amigas...

A queixa matema não se faz esperar: a sra. C. telefona e pede para falar "com essa psicóloga que manipula sua fillha" . E lhe expressa então, de modo muito agressivo, sua impossibilidade de suportar que sua filha chegue duas horas mais tarde do que o necessário, alegando que, no inverno, anoitece mais cedo e que ela deve ajudá-la com os afazeres domésticos, com o preparo das refeiç̧⿻s...

A terapeuta assinala que sua filha tem 32 anos e que então seria desejável discutir tudo isso diretamente com ela. Nos dias que se seguem, a mãe pressiona, mas Elise suporta bem essa pressão. E começa até mesmo a sair à noite e nos fins de semana.

Telefonema da mãe: "Vou pôr Elise na Clínica Mon Repos", ela faz besteiras, afinal, sei melhor do que vocês o que é bompara ela, fui eu que a fiz" . Podemos nos perguntar que "descanso" e, sobretudo, sobre o descanso de quem se trata aqui.

A terapeuta decide então ligar, a pedido de Ellise, para o psiquiatra que a acompanha uma vez por mês para prescrever seu tratamento, na tentativa de introduzir um terceiro, a palavra de um terceiro. Por sorte, esse médico é totalmente receptivo à proposta, ele acha que Elise está bem, e consegue dissuadir a mãe de uma hospitalização sem nenhum motivo.

O tempo passa, Elise encontra um rapaz, estabelece uma relação amorosa, desabrocha, faz, juntamente com a assistente social da equipe, um projeto de trabalho em atelier protegido e que irá se concretizar.

Evidentemente, Elise permanece alienada ao desejo de sua mãe e lhe conta tudo sobre sua relação amorosa. A mãe, queixando-se de que "ignora o motivo pelo qual tal infel icidade abate-se sobre ela", remete-lhe uma imagem degradada de si mesma, pondo o amor no real do sexo, imagem talvez idêntica àquela, única, que ela pôde outrora sustentar do lado do espelho, e diz: "você é uma puta, felizmente seu pai está morto, pelo menos ele está feliz, ele sofreria muito em ver no que você se tomou", sabendo também o quanto é fácil jogar, de modo perverso, com o sentimento de culpa de Elise, que adorava seu pai havia pouco falecido e por quem ela ainda chora. Um estranho no ninho...

"Quando o dbjeto escapa, o sujeito passa do amor ao ódio." 
Nenhuma ambivalência na mãe de Elise. Muito ódio vindo de uma falha no domínio sobre o objeto, provocando sem dúvida uma falência do eu nessa mulher. Podemos supor que os propásitos arcaicas de sua queixa revelam talvez algo de seu laço etemo com sua mãe, da indiferença que talvez tenha velado esse laço, uma questão em torno do abandono, de um vazio que a criança, dbjeto perfeitamente adequado, poderia ter preenchido, evitando assim o horror.

O dojeto escapa, toma-se indisponível, separa-se, ausenta-se: não mais podendo preencher exclusivamente as funções de objeto de gozo, ele toma-se objeto de queixa sobre - qual tudo será tentado para o reencontro de uma posição de todopoder que o mantenha absolutamente dependente (insultos, culpa...) , tentativa que se expressa então na mãe narcisicamente ferida. Mãe que é mais uma vez levada à sua incompletude, mais uma vez confrontada à desilusão que consiste em perceber que seu fil ho sobrevive além de seu olhar. A ilusão repousaria aqui sobre uma criança nunca desmamada, isto é, preenchedora e preenchida.

Propomos nesse caso a hipótese de que a queixa aqui é paradoxalmente saudável e situa-se no lugar da passagem ao ato. A criança tomada dojeto da queixa, por um lado, sai da posição de dbjeto real em que a havia pasto o fantasma matemo, e, por outro lado, no mesmo movimento, torna-se lugar de inscrição de elementos da história matema não elaborada, sob a figura de sintomas, como para o neurótico de base, com duas vantagens: a inscrição dessa criança na cadeia geracional e o fato de que um sintoma se analise. Talvez possamos então, a partir da queixa materna, tentar fazer com que a criança tenda a se tomar objeto e causa não mais do desejo exclusivo de sua mãe, mas abjeto e causa de um pensamento, istoé, poder atribuir-se um lugar desujeito.

A queixa não diz mais respeito ao terapeuta "que faz mal à criança", mas à própria criança. Talvez tenhamos passado aqui de uma criança odiada sem ambivalência, isto é, sem amor, para uma criança de que nos queixamos por amá-la.

Isso posto, o fato de que a mãe se queixa do filho faz com que ele continue a fazer a economia do reconhecimento da falta e da perda do abjeto na origem da divisão estruturante de todo sujeito. A queixa sobre aquele que é perdido impediria de algum modo captar efetivamente aquilo que foi perdido.

Da mesma forma que a criança, para viver, deve renunciar ao dojeto inicial, vimos que a mãe, em contrapartida, para deixá-lo viver, deve renunciar ao fi tho, isto é, deve conceber-se como limitada, castrada, definitivamente não todb-poderosa, devendo ver seu gozo do outro temperado, barrada por um corte simbólico, e, finalmente, talvez, deixar de queixar-se (no filme de Almodóvar Tudo sobre minha mãe, uma criança morre inevitavelmente no real, e o filme nos mostra a queixa infinita de uma mãe enlutada que vai, um pouco depois, buscar e tentar apoiar-se numa função 
patema que só poderá encamar-se nos traços de um homem transexual: será que é isto que está contido no "tudo" do título?) .

Aqui se inscreve a questão da ligação entre a queixa e o toob-poder materno. Filho-todo de uma mãe-toda, dito de outro modo, a mãe que ama o filho com um amor incondicional (justamente, a condição é o não-toob, a castração) espera em retorno um amor do mesmo peso, istoé, àaltura do "sacrifícid" .

Esse último significa-se, principalmente na psicose, por essa submissão, essa alienação ao desejo da mãe, de que nada, isto é, nenhum nome do pai, vem separar a criança. A mãe é vivida aqui como única portadbra do desejo e exerce sobre a criança um total arbítrio. É por isso que a mãe, ao ver as sessões terapêuticas margearem o infinito infantil para fazer da criança um ser incompleto, põe-se a queixar-se, encontrando na queixa a última proteção contra a falta, e a própria criança não émais suficiente.

Aqueixa garantiria aqui finalmente a permanência do objeto, e, assinalanob a ruptura, evitaria ainda para a mãe a questão da perda e do luto.

Se nada vem em auxílio à elaboração dessa infinita nostalgia matema de uma ruptura impossível, se nada vem em auxílio ao discurso dessa mãe, na luta contra impossíveis limites, então a queixa deixa livre curso ao ódio, que corre o risco de causar dano ao dojeto, e até mesmo de destruí-1o, e a partir daí podemos evocar a passagem ao ato anteriormente citada. 
Sem chegar a essa situação extrema que é a psicose, de modo mais clássico e mais banal, encontramos um grande número de mães às voltas com crises pubertárias (as suas próprias e as de seus adolescentes) que vêm se queixar, ou, mais exatamente, vêm "dar queixa contra" seu adolescente. Freud (1915) , em "Luto e melancolia", diz "este velho sentidb do alenão: queixas contra".

Ora, a adolescência é o tempo em que a separação repete-se, para adquirir dessa vez aspectos de definitivo e de radicalidade. Aqui, queixar-se do adolescente recobre a nostalgia de um tempo anterior à ruptura que está sendo integrado como para sempre perdido. A queixa é nostalgia e visa a abolir a distância, certamente, mas também o tempo. Um pouco do mesmo modo com que o adolescente vive, na puberdade, conflitos já atravessados, a mãe confronta-se à perda já amplamente entrevista, mas sempre contomada. Como vimos, ela não estava totalmente enganada na neurose, e permanecia, em contrapartida, confortada na ilusão de uma unidade fusional etema na psicose.

Pensamos nesse paciente esquizofrênico que matou a mãe há quatro anos e até hoje sonha que a está matando: lembremos que o sonho é uma tentativa de realização do desejo, segundo Freud.

Como para reforçar essa dor matema, o adolescente, não contente em confrontar sua mãe à perda da i lusão de seu toodo-poder, comporta-se, por meio de sua "crise", como se não a amasse mais, persuadindo-a ainda mais daquilo que Freud chama "a perda do amor do abjeto" .

É assim que, com freqüência, degeneram o que chamamos habitualmente de "crises adblescentes" : no horizonte das violências, há este ser perdidb, o adblescente, acusadb pela queixa. O problema é que toda acusação demanda reparação, e vemos assim mães que perseguem seus adblescentes simplesmente porque são adblescentes. Enquanto "a adolescência é simplesmente uma doença juvenil que sara com o tempo", diz Winnicott (1969) . O sentimento de abandono que a mãe pode sentir relança o perigo da perda de amor, e assim a mãe dá queixa contra ele ou se perde no ódio.

\section{CONCLUS ̃̃O}

Concluiremos com a proposta de imaginar que a queixa matema de uma mãe de sujeito psicótico repousa sobre três pontos: sobre a separação que está se realizando, que pode significar a autonomização da criança, sobre o limite do domínio que gera este distanciamento, e, finalmente, sobre a perda de uma certeza, 
esta também totalizante, a do amor do dojeto.

Dizendo-se sempre e para sempre não culpada, a mãe do psicótico situa-se então como vítima, o que pode ter como efeito conduzir a criança a seu lugar, o de estar submetida ao capricho da mãe até evitar-Ihe esta questão, a questão da ambivalência em relação ao objeto perdido.

É por isso que o trabalho com pacientes psicóticos édifícil, pois a psicose é difícil, certamente, mas também porque o lugar da criança no fantasma materno não é um lugar que pode ser deixado sem mais nem menos: todo um equilí́brio psicopatológico repousa aí e desaba tão logo a posição psíquica de um ou de attro se desestabiliza.

O trabalho terapêtico consiste, entre atras coisas, emproporcionar a emergência, para o sujeito, das palavras passíveis sobre o luto que visariam fazer da relação mãe/fi lho não mais um modelo intransponível, mas uma lembrança.

\section{REFERÊNCIAS BIBLIOGRÁFICAS}

Almodbvar, P. (1999) . Taut sur ma mère (filme).

Dolto, F. (1984) . L'image inconsciente du conps. Paris: Saril.

Freud, S. (1905) . Trois essais sur la théoriese xuelle. Paris: Gallimard, 1989.

(1908-9) . Le petit Hans. In Cing psychanalyses. Paris: PuF, 197.

(1915) . Deuil et mélancolie. In MÉtapsychologie. Paris: Gallimard, 1968.

(1932-3) . Nouvelles conférences d'introouction à la psychanalyse. Paris:
Gallimard, 1984.

Jacdbi, B. (1998). Les mots et la plainte. Toulase: Erès.

Iacan, J. (1973) . L'étardit. Scilicet, 4. (1956-7) . Séminaire, Livire IV, La relationd'dojet. Paris: Sevil, 1994. (1957-8) . Séminaire, Livre V, Les formations de l'inconscient. Paris: Seuil, 1998.

(1991) . Séminaire Livre XVII,

L'eners de lapsychanalyse, Paris: Saril.

Winnicott, D. W. (1969). De la pédiatrie à la psychanalyse. Paris: Payct.

N O T A

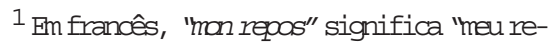
pouso" (N. da T.) .
Recebidb em janeiro/2004. Aceito em março/2004. 